\title{
Macular Degeneration and Treatment
}

\author{
Mine Ün ${ }^{1}$, Sedef Öztürk²
}

\section{MACULA DEGENERATION}

Age-related macular degeneration (AMD) is the most important cause of central vision loss in people over 50 years of age. ${ }^{[1]}$

Nowadays it is known that macular degeneration occurs due to damage of neurons. ${ }^{[2]}$ This disease occurs as a complicated degeneration of the macula involving the photoreceptor, retinal pigment epithelium, Bruch's membrane and choriocapillaris. ${ }^{[3,4]}$

The incidence was found to be $10 \%$ between the ages of $65-75$ and $25 \%$ above the age of 75 , so it is an important public health problem. ${ }^{[3,4]}$

Macular degeneration is divided into two main groups: exudative AMD and atrophic AMD. The exudative type accounts for about $10 \%$ of cases and is characterized by the formation of new vessels from the choroid located at the lower part of the macula. The atrophic type accounts for about $90 \%$ of cases and is characterized by a slow decline in vision over many years, photoreceptor loss and geographical atrophy. ${ }^{[5]}$

\section{ATROPHIC TYPE AMD}

Atrophic (non-exudative) AMD has retinal pigment epithelium and photoreceptor loss. It is

\footnotetext{
'Istanbul Aydın University Medical Faculty, Istanbul, Turkey

${ }^{2}$ Demiroğlu Bilim University Faculty of Medicine, Istanbul, Turkey
}

Correspondence: Mine Ün. İstanbul Aydın Üniversitesi Tıp Fakültesi, 34295 Sefaköy, Küçükçekmece, İstanbul, Türkiye.

E-mail: unmine13@gmail.com

Cite this article as: Ün M, Öztürk S. Macular Degeneration and Treatment. JEB Med Sci 2020;1(1):1-5.

doi: $10.5606 /$ jebms.2020.75600

Received : : August 23, 2019

๑2020 Journal of Experimental and Basic Medical Sciences. All rights reserved.

\section{ABSTRACT}

Macular degeneration is an important cause of visual loss in the elderly. While it has been a problem that has not been completely cured until recently, it has been possible to prevent the progression of the disease with some applications in the last few years and to delay the resulting visual loss.

Keywords: Age related macular degeneration, experimental studies, treatment.

characterized by the accumulation of yellow crystals called drusen in the macula, and retinal atrophy areas form large patchy geographic atrophy areas in later periods (Figure 1). Generally, visual loss develops over the years in the atrophic AMD, while the exudative type manifests more rapidly. ${ }^{[6]}$

Although atrophic type constitutes approximately $90 \%$ of all AMD patients, $80-90 \%$ exudative type is responsible for visual loss. ${ }^{[6]}$

Approximately $10-20 \%$ of atrophic AMD patients progress to exudative AMD. ${ }^{[6]}$

\section{EXUDATIVE TYPE AMD}

The exudative (neovascular) type is characterized by the formation of new vessels developing from the

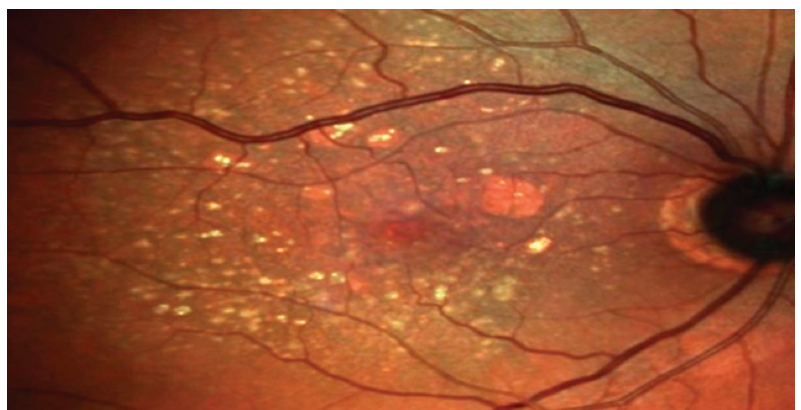

Figure 1. Yellow crystals called drusen appearing in the macula. ${ }^{[6]}$ 
pathological choroid under the retina in addition to retinal pigment epithelium and photoreceptor loss. ${ }^{[7]}$

Subretinal fluid, subretinal hemorrhage, retinal pigment epithelium (RPE) detachment causes symptoms such as central scotoma, metamorphopsy and reading difficulties (Figure 2). ${ }^{[7]}$

A typical symptom of exudative AMD patients is sudden onset and insidious, painless central visual loss. When subretinal hemorrhage develops due to the formation of a new choroidal vessel, the cases show sudden symptoms. However, when shallow subretinal fluid accumulation or retinal pigment epithelium detachment develops, the disease has an insidious course..$^{[7]}$

\section{EXPERIMENTAL AND CLINICAL TREATMENT STUDIES}

\section{Antioxidants and Vitamins}

In the Age Related Eye Disease Study 1-2 (AREDS1-2) studies, a combination of $500 \mathrm{mg}$ of vitamin C, $400 \mathrm{IU}$ of vitamin E, $80 \mathrm{mg}$ of zinc, $2 \mathrm{mg}$ of copper, lutein and zeaxanthin has been shown to reduce dry AMD progression. ${ }^{[8-11]}$

Ongoing studies have shown that Crocetin is a carotenoid dicarboxylicacid derivative, experimentally inhibiting caspase activity, reducing oxidative stress and protecting against retinal damage caused by light exposure. ${ }^{[12]}$

In addition, pyridoxine (B6), folic acid (B9), and cyanocobalamin (B12), which are sub-classes of vitamin $B$, are known to reduce the risk of vascular disease by decreasing serum homocystine levels as well as antioxidant effects. A randomized clinical trial reported a reduced risk of $A M D$ in individuals receiving $B 6, B 9$ and $B 12$ daily. ${ }^{[13]}$

\section{Visual Cycle Inhibitors}

Agents of this class are used to reduce the accumulation of toxic products such as lipofuscin and $\mathrm{N}$-retinylidene- $\mathrm{N}$-retinylethanolamine (A2E) released by visual cycle and prevent the death of retinal pigment epithelium and photoreceptor cells. ${ }^{[14]}$

Fenretinide inhibits the formation of transthyretinRBP complex by inhibiting all-trans retinol binding of retinal binding protein (RBP). Dose dependentreversible reduction of $\mathrm{RBP}$ and retinol circulation reduces indirectly lipofuscin and A2E formation. ${ }^{[14]}$

A placebo-controlled study with this Phase-2 molecule showed a decrease in lesion development in patients with geographic atrophy after oral administration of 100 and $300 \mathrm{mg} /$ day. In addition, a $45 \%$ reduction in choroidal neovascularization was observed in the group receiving Fenretinide irrespective of its dose. ${ }^{[14]}$

\section{Anti-Inflammatory Agents}

Dry type AMD, inflammatory deposits such as retinal pigment epithelial cells, bruch membrane and choroid lipofuscin have been shown to be effective in the process of chronic inflammation. ${ }^{[15-17]}$ Therefore, the effect of corticosteroids on the antiinflammatory and anti-angiogenic effects of dry type AMD is under investigation. ${ }^{[18]}$

The lluvien, which is a molecule producted for this purpose, is an injectable form of corticosteroid implant in Phase-2 study in AMD patients. ${ }^{[18]}$

One of these agents, POT-4, binds to complement factor-3 and thereby inhibits the proteolysis required for $\mathrm{C} 3 \mathrm{a}-\mathrm{C} 3 \mathrm{~b}$ formation. The Phase-1 study of this molecule, which was administered intravitreally and has slow release effect was terminated in six months. ${ }^{[19]}$
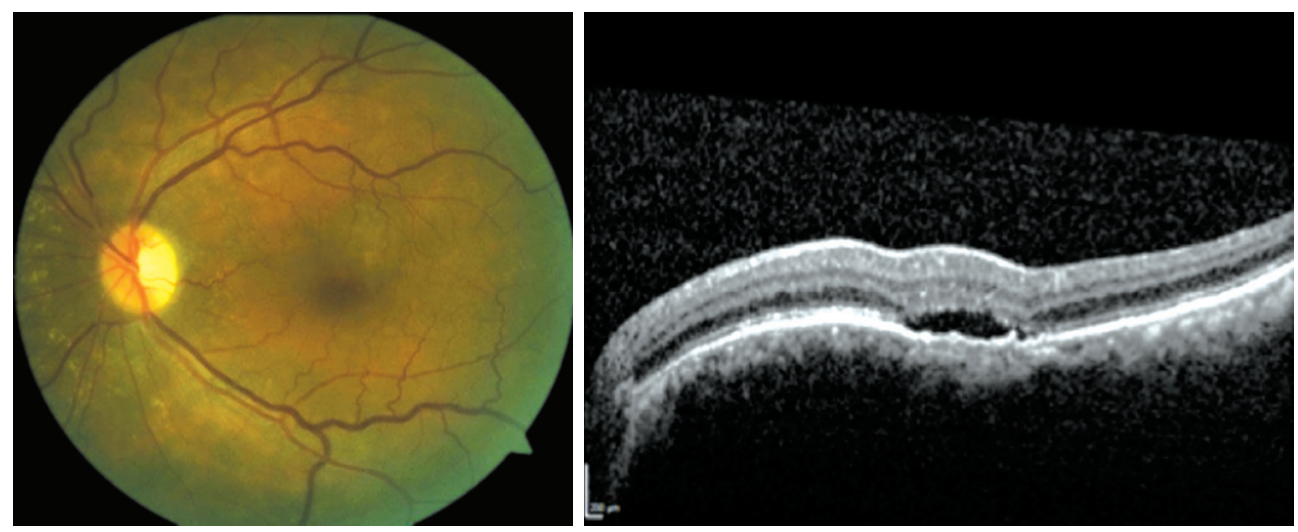

Figure 2. Retinal pigment epithelium detachment. Color fundus photograph and OCT image. ${ }^{[6]}$ 
Another agent, ARC-1905 is an anti-C5 aptamer which can be administered intravitreally and its Phase-1 studies are still in progress. ${ }^{[20]}$

Eculizumab is an approved molecule by FDA for its use in the treatment of paroxysmal nocturnal hemoglobinuria. This drug is a humanized monoclonal antibody that blocks complement factor-5 (C5) and is still in the Phase-2 study stage. However, when it's administered with an intravenous form in AMD patients, it did not show an effective change in the rate of geographic atrophy progression and drusen volume in a placebo-controlled Phase-2 study. ${ }^{[21,22]}$

The LGF-316 molecule is an another anti-C5 antibody which can be administered intravitreally. The results of Phase-2 study have not yet been published. ${ }^{[23]}$

The lampalizumab molecule is a monoclonal Fab fragment produced against factor- $D$ in the alternative complement pathway. As a result of the Phase-2 study of this intravitreally administered molecule, 143 patients with bilateral geographic atrophy were followed up with $5 \mathrm{mg}, 10 \mathrm{mg}$ and sham treatment monthly and in every two months. Although the effect started in the first six months, a $24 \%$ decrease in the progression of geographic atrophy was found at an average follow-up of 18 months. ${ }^{[24]}$

After monthly injection of lampalizumab, geographical atrophy patients with a complement factor inhibitor (CFI) mutation showed a $44 \%$ reduction in the progression of geographic atrophy over an 18-months period. ${ }^{[24,25]}$

One of these agents, GSK933776, is a monoclonal humanized antibody produced against intravenously administered $\beta$-amyloid. This antibody has been shown to reduce the accumulation of Beta-amyloid and C3a in the Bruch's membranes of mice. The Phase-2 study is still ongoing. ${ }^{[26]}$

\section{Choroid Blood Flow Regulating Agents}

It is thought that decreasing choroidal blood flow that provides oxygen and feeding environment to the outer retina layer with advancing age may play a role in the pathogenesis of AMD. Choroidal blood flow regulating agents have been developed for this purpose. $^{[27]}$

MC-1101 molecule is produced in topical drop form and increases the choroidal blood flow by triggering the production of nitric oxide which causes the dilation of the vessels. As a result of the Phase-1 study, it has been pointed out to increase the choroidal blood flow velocity and volume in AMD and also have anti-inflammatory and antioxidant effects. ${ }^{[27]}$

Moxaverine molecule is a phosphodiesterase inhibitor that increases the choroidal mean flow rate in the ophthalmic artery and posterior ciliary artery. ${ }^{[28]}$

\section{Stem Cell Transplantation}

Another form of treatment is stem cell transplantation. Two different studies are carried out in this field. The first one is the Advanced Cell Technology (ACT) method, which uses human embryogenic stem cells. ${ }^{[29]}$

There are two separate Phase 1-2 studies evaluating retinal pigment epithelium-induced human embryogenic stem cell therapy in dry type AMD and Stargart macular dystrophy. The first study was a subretinal infusion of MA09-hRPE cells. The second study was a Phase 1-2 study evaluating the tolerability and safety of MA09-hRPE cell therapy in advanced dry AMD patients. ${ }^{[30]}$

CNTO 2476 is a method that uses umbilicalderived stem cells. Stem cells are injected subretinally by microcatheter and endoscope by external approach. The Phase 1-2 study is still ongoing in patients with geographic atrophy. ${ }^{[22]}$

In conclusion, anti-VEGF drugs are the most current treatment option that can be used safely in the treatment of AMD. Although the treatment modalities, which increase the injection intervals after loading treatment with three monthly injections other than monthly injection, are tried, however the best results are obtained with monthly injection treatments. ${ }^{[22,25-30]}$

However, monthly injection reduces patient compliance due to the risk of complications and the need to monitor patients frequently. When evaluated in terms of efficacy, the results obtained from the studies and clinical applications are still far from being satisfactory and it is possible to control serious visual loss with these treatments. ${ }^{[22,25-30]}$

Although there is a long way to go, many promising treatment options are being developed for both types of the disease. Among these studies, especially molecular studies on neuroprotection and stem cell studies are thought to be promising for the future. ${ }^{[22,25-30]}$ 


\section{Declaration of conflicting interests}

The authors declared no conflicts of interest with respect to the authorship and/or publication of this article.

\section{Funding}

The authors received no financial support for the research and/or authorship of this article.

\section{REFERENCES}

1. Bressler NM. Age related macular degeneration. New hope for a common problem comes from photodynamic therapy. BMJ 2000;321:1425-7.

2. Klein R. Epidemiology of age-related macular degeneration. In: Penfold PL, Provis JM editors. Macular Degeneration. Berlin Heidelberg: Springer-Verlag; 2005. p. 79-101.

3. Lotery A, Xu X, Zlatava G, Loftus J. Burden of illness, visual impairment and health resource utilisation of patients with neovascular age-related macular degeneration: results from the UK cohort of a five-country crosssectional study. Br J Ophthalmol 2007;91:1303-7.

4. Liu TY, Shah AR, Del Priore LV. Progression of lesion size in untreated eyes with exudative age-related macular degeneration: a meta-analysis using Lineweaver-Burk plots. JAMA Ophthalmol 2013;131:335-40.

5. Singer M. Advances in the management of macular degeneration. F1000Prime Rep 2014;6:29.

6. Bowes Rickman C, Farsiu S, Toth CA, Klingeborn M. Dry age-related macular degeneration: mechanisms, therapeutic targets, and imaging. Invest Ophthalmol Vis Sci 2013;54:ORSF68-80.

7. Nowak JZ. Age-related macular degeneration (AMD): pathogenesis and therapy. Pharmacol Rep 2006;58:353-63.

8. Clemons TE, Milton RC, Klein R, Seddon JM, Ferris FL 3rd; Age-Related Eye Disease Study Research Group. Risk factors for the incidence of Advanced Age-Related Macular Degeneration in the Age-Related Eye Disease Study (AREDS) AREDS report no. 19. Ophthalmology 2005;112:533-9.

9. AREDS2 Research Group, Chew EY, Clemons T, SanGiovanni JP, Danis R, Domalpally A, et al. The AgeRelated Eye Disease Study 2 (AREDS2): study design and baseline characteristics (AREDS2 report number 1). Ophthalmology 2012;119:2282-9.

10. Age-Related Eye Disease Study Research Group. The AgeRelated Eye Disease Study (AREDS): design implications. AREDS report no. 1. Control Clin Trials 1999;20:573-600.

11. Age-Related Eye Disease Study 2 Research Group. Lutein + zeaxanthin and omega-3 fatty acids for age-related macular degeneration: the Age-Related Eye Disease Study 2 (AREDS2) randomized clinical trial. JAMA 2013;309:2005-15.

12. Maccarone R, Di Marco S, Bisti S. Saffron supplement maintains morphology and function after exposure to damaging light in mammalian retina. Invest Ophthalmol Vis Sci 2008;49:1254-61.
13. Christen WG, Glynn RJ, Chew EY, Albert CM, Manson JE. Folic acid, pyridoxine, and cyanocobalamin combination treatment and age-related macular degeneration in women: the Women's Antioxidant and Folic Acid Cardiovascular Study. Arch Intern Med 2009;169:335-41.

14. Mata NL, Lichter JB, Vogel R, Han Y, Bui TV, Singerman LJ. Investigation of oral fenretinide for treatment of geographic atrophy in age-related macular degeneration. Retina 2013;33:498-507.

15. Anderson DH, Mullins RF, Hageman GS, Johnson LV. A role for local inflammation in the formation of drusen in the aging eye. Am J Ophthalmol 2002;134:411-31.

16. Gehrs KM, Jackson JR, Brown EN, Allikmets R, Hageman GS. Complement, age-related macular degeneration and a vision of the future. Arch Ophthalmol 2010;128:349-58.

17. Cherepanoff S, McMenamin P, Gillies MC, Kettle E, Sarks $\mathrm{SH}$. Bruch's membrane and choroidal macrophages in early and advanced age-related macular degeneration. Br J Ophthalmol 2010;94:918-25.

18. Sanford M. Fluocinolone acetonide intravitreal implant (lluvien ${ }^{\circledast}$ ): in diabetic macular oedema. Drugs 2013;73:187-93.

19. Safety of Intravitreal POT-4 Therapy for Patients with Neovascular Age-Related Macular Degeneration (AMD) (ASaP). Available at: http://clinicaltrials.gov/ct2/ show/NCT00473928?term=pot-4\&rank=1. [Accessed: March 29, 2010].

20. Available at: http://www.ophthotech.com/products/ arc1905/ [Accessed: March 29, 2010].

21. Yehoshua Z, de Amorim Garcia Filho CA, Nunes RP, Gregori G, Penha FM, Moshfeghi AA, et al. Systemic complement inhibition with eculizumab for geographic atrophy in age-related macular degeneration: the COMPLETE study. Ophthalmology 2014;121:693-701.

22. Hariri A, Nittala MG, Sadda SR. Outer retinal tubulation as a predictor of the enlargement amount of geographic atrophy in age-related macular degeneration. Ophthalmology 2015;122:407-13.

23. Available at: http://www.amd.org/lfg316-for-dry-amdrecruiting/ [Accessed: October 24, 2009]

24. Leung $E$, Landa G. Update on current and future novel therapies for dry age-related macular degeneration. Expert Rev Clin Pharmacol 2013;6:565-79.

25. Available at: https://clinicaltrials.gov/ct2/show/ NCT01577381 [Accessed: July 12, 2014]

26. Leyhe $T$, Andreasen $N$, Simeoni $M$, Reich A, von Arnim CA, Tong $X$, et al. Modulation of $\beta$-amyloid by a single dose of GSK933776 in patients with mild Alzheimer's disease: a phase I study. Alzheimers Res Ther 2014;6:19.

27. Buschini E, Fea AM, Lavia CA, Nassisi M, Pignata G, Zola $M$, et al. Recent developments in the management of dry age-related macular degeneration. Clin Ophthalmol 2015;9:563-74.

28. Pemp B, Garhofer G, Lasta M, Schmidl D, Wolzt M, Schmetterer $L$. The effects of moxaverine on ocular blood flow in patients with age-related macular degeneration or primary open angle glaucoma and in healthy control subjects. Acta Ophthalmol 2012;90:139-45. 
29. Lu B, Malcuit C, Wang S, Girman S, Francis P, Lemieux L, et al. Long-term safety and function of RPE from human embryonic stem cells in preclinical models of macular degeneration. Stem Cells 2009;27:2126-35.

30. Schwartz SD, Regillo CD, Lam BL, Eliott D, Rosenfeld PJ,
Gregori NZ, et al. Human embryonic stem cell-derived retinal pigment epithelium in patients with agerelated macular degeneration and Stargardt's macular dystrophy: follow-up of two open-label phase 1/2 studies. Lancet 2015;385:509-16. 